https://ejournal.iai-tribakti.ac.id/index.php/perbankan

\title{
Korelasi Merger Tiga Bank Syariah dan Kesadaran Masyarakat Terhadap Produk Perbankan Syariah
}

\section{Merger Correlation of Three Sharia Banks and Public Awareness of Sharia Banking Products}

\author{
Bagus Romadhon ${ }^{1}$, Sutantri ${ }^{2}$ \\ ${ }^{1}$ Institut Agama Islam Tribakti, ${ }^{2}$ Institut Agama Islam Tribakti \\ ${ }^{1}$ bagusromadhon60@gmail.com, ${ }^{2}$ tantrigirl66@gmail.com
}

\begin{abstract}
Islamic banking has just made a new history. Three state-owned Islamic banks have successfully merged under the name Bank Syariah Indonesia (BSI). It is recorded that the performance of the first semester of 2020, the total assets of BSI as a result of the merger reached Rp. 214.6 trillion with a core capital of more than Rp. 20.4 trillion. With the value of these assets and core capital, the merged Islamic bank will enter the ranks of the top 10 largest banks in Indonesia in terms of assets from a market capitalization perspective. However, public knowledge of Islamic banking products in Indonesia has not been satisfactory. A survey conducted by the Financial Services Authority (OJK) in 2016 showed that only $21.84 \%$ of the public used Islamic banking products. This research is a literature research and the author's critical thinking. By the nature of the research is descriptive. Primary sources are journals and other scientific works. Secondary data from supporting books and websites. The analysis applied is quantitative. Based on this research, it is concluded that there are several factors that affect public awareness of Islamic banking products including: a. Lack of public awareness about Islamic banks. b. Limited operational network of Islamic banks $c$. The socialization carried out by syari'ah banks is still not massive enough to affect one's perceptive power and mindset. Meanwhile, the most important recommendation from researchers for BSI is to continue to provide socialization of Islamic banking products.
\end{abstract}

Keywords: Mergers, Public Awareness, Sharia banking products 


\title{
Bagus Romadhon | Korelasi Merger Tiga Bank...
}

\begin{abstract}
Abstrak
Perbankan Syariah baru saja mencatatkan sejarah baru. Tiga Bank Syariah milik Pemerintah berhasil merger dengan nama Bank Syariah Indonesia (BSI). Tercatat kinerja semester I-2020 total aset BSI hasil merger mencapai Rp 214,6 triliun dengan modal inti lebih dari $\mathrm{Rp} 20,4$ triliun. Dengan nilai aset dan modal inti tersebut, bank syariah hasil merger akan masuk jajaran 10 besar bank terbesar di Indonesia dari sisi aset segi kapitalisasi pasar. Namun begitu, pengetahuan masyarakat akan produk perbankan syariah di Indonesia belum memuaskan. Survei yang dilakukan oleh Otoritas Jasa Keuangan (OJK) tahun 2016 menunjukan bahwa hanya 21,84\% masyarakat yang menggunakan terhadap produk perbankan syariah. Penelitian ini merupakan penelitian Kepustakaan dan Pemikiran Kritis Penulis. Dengan sifat penelitian adalah deskriptif. Sumber primer adalah jurnal dan karya Ilmiah lainya. Data sekunder dari buku penunjang dan website. Analisa yang diterapkan adalah kuantitatif. Berdasarkan penelitian ini, menyimpulkan bahwa ada beberapa faktor yang mempengaruhi kesadaran masyarakat akan produk perbankan syariah diantaranya a. Kurangnya kesadaran masyarakat tentang bank syariah. b. Jaringan operasional bank syariah yang masih terbatas c. Sosialisasi yang dilakukan bank syari'ah masih kurang massif mempengaruhi terhadap daya tangkap dan pola pikir seseorang. Sedangkan usulan dari peneliti terhadap BSI yang paling utama adalah terus memberikan sosialisasi akan produk perbankan syariah.
\end{abstract}

Kata Kunci: Merger, Kesadaran Masyarakat, Produk perbankan Syariah

\section{Pendahuluan}

Perbankan Syariah Indonesia menjadi perbincangan hangat awal tahun ini. Hal yang lama dinantikan masyarakat Indonesia menjadi kenyataan. Begitu pula para pengamat ekonomi di Indonesia. Tiga Bank Syariah milik Pemerintah, Yakni BRI Syariah, Bank Syariah Mandiri, dan BNI Syariah akhirnya menjadi satu kesatuan dan berubah nama menjadi Bank Syariah Indonesia (BSI). Banyak masyarakat yang optimis BSI akan 


\section{Bagus Romadhon | Korelasi Merger Tiga Bank...}

membawa dampak luar biasa pada perbankan syariah di Indonesia. Sintimen positif pun hadir dari berbagai pelaku ekonomi di Indonesia.

Menurut Banjaran Surya Indrastomo, pengamat sekaligus pengajar Studi Ekonomi Islam di Uineversitas Indonesia, bank syariah hasil merger memiliki prospek cerah karena akan mewarisi hal-hal baik dari tiga entitas yang terlibat. Hal itu membuat bank syariah hasil merger memiliki kekuatan komplit untuk memperbesar pangsa pasar keuangan syariah. ${ }^{1}$

Seperti yang sudah dikenal hingga saat ini, ketiga Bank Syariah yang sudah bermerger, memiliki keunggulan tersendiri. Semisal Bank Syariah Mandiri, yang terkenal dengan sistem kerja dan profesionalitas kerjanya, Bank BNI syariah dengan kemampuan inovasi, serta BRI syariah dengan pemahaman lokal dan regional. Sehingga banyak yang memprediksi BSI akan menjadi lincah dan semakin kompetitif dengan Bank Konvensial yang saat ini lebih dominan. ${ }^{2}$

Tantangan BSI tentu tidak semudah yang dibayangkan. Dalam beberapa penelitian menjelaskan bahwa kesadaran masyarakat Indonesia masih sangat minim akan produk Perbankan Syariah. Hal itu dijelaskan dalam survei yang dilakukan oleh Otoritas Jasa Keuangan (OJK) pada tahun 2016 silam. Dalam survei tersebut menjelaskan masyarakat Indonesia yang well literate akan produk perbankan syariah hanya sebesar $21,84 \%{ }^{3}$

Dimana seseorang dikatakan well literate jika ia memiliki pengetahuan dan keyakinan tentang lembaga keuangan serta produk dan jasa keuangan, termasuk fitur, manfaat dan risiko, hak dan kewajiban terkait produk dan jasa keuangan, serta memiliki keterampilan dalam menggunakan produk dan jasa keuangan

\footnotetext{
${ }^{1}$ https://www.wartaekonomi.co.id/read329477/BSI

${ }^{2}$ https://www.wartaekonomi.co.id/read329477/BSI

${ }^{3}$ Anriza Witi Nasution, Marlya Fatira AK EQUILIBRIUM: Jurnal Ekonomi Syariah Volume 7, Nomor 1, 2019, $40-63$
} 


\section{Bagus Romadhon | Korelasi Merger Tiga Bank...}

Sedangkan setahun berselang, yakni tahun 2017, OJK menjelaskan secara rata-rata dari 10 ribu yang menggunakan produk perbankan, hanya 2 ribu yang menggunakan produk perbankan syariah. Survei ini tentu saja menjadi sebuah ironi perbankan syariah di Indonesia. ${ }^{4}$

Sebagai negara berpenduduk muslim di dunia, dengan total penduduk Indonesia merupakan negara muslim terbesar dunia. Berdasarkan data Globalreligiusfuture, penduduk Indonesia yang beragama Islam pada 2010 mencapai 209,12 juta jiwa atau sekitar $87 \%$ dari total populasi. ${ }^{5}$

Kemudian pada 2020, penduduk muslim Indonesia diperkirakan akan mencapai 229,62 juta jiwa. Seharusnya produk perbankan syariah memiliki pangsa yang sangat besar. Sangat potensial jika dapat dimanfaatkan dengan baik mergernya ketiga Bank Syariah ini. ${ }^{6}$

Disisi lain, dengan ada merger ini Sumber Daya Insani yang akan mengelola BSI akan semakin banyak. Sehingga harapannya akan tercipta kompentensi karyawan yang semakin berkualitas dan optimal.

Saat ini, BSI memiliki 1.120 cabang di seluruh Indonesia.Jumlah kantor tersebut lebih banyak dari dua bank yang lebih besar dari BSI, yakni BTN yang memiliki kantor cabang 880 buah (termasuk kantor kas), dan Bank CIMB Niaga yang hanya punya 466 kantor. Jumlah karyawan BSI juga cukup besar, yakni 20.094 orang. ${ }^{7}$

\footnotetext{
${ }^{4}$ Anriza Witi Nasution, Marlya Fatira AK EQUILIBRIUM: Jurnal Ekonomi Syariah Volume 7, Nomor 1, 2019, $40-63$

5 https://databoks.katadata.co.id/datapublish/2019/09/25/indonesia-negara-denganpenduduk-muslim-terbesar-dunia

6 https://databoks.katadata.co.id/datapublish/2019/09/25/indonesia-negara-denganpenduduk-muslim-terbesar-dunia syariah-indonesia

https://lokadata.id/artikel/pengamat-jumlah-sdm-dan-cabang-jadi-tantangan-bank-
} 


\section{Bagus Romadhon | Korelasi Merger Tiga Bank...}

Selain itu, kantor BSI menjadi semakin banyak. Tersebar di berbagai Kota di Indonesia. Bahkan di daerah aksenya kurang representative pun sudah tersedia pelayanan di Kantor Cabangnya.

Beberapa penelitian tentang kesadaran masyarakat akan Produk Bank Syariah masih rendah. Hasil penelitian Faradila (2016) menunjukkan bahwa jenis kelamin, program studi, IPK, tingkat pendidikan orang tua dan financial socialization agents secara simultan berpengaruh terhadap kesadaran literasi keuangan Bank Syariah terhadap mahasiswa S1 Fakultas Ekonomi Universitas Andalas. Hal itu menandakan faktor-faktor yang disebutkan diatas berperngaruh positif akan pengetahuan Mahasiswa S1 Fakultas Syariah di Universitas Andalas. ${ }^{8}$

Selanjutnya, ada hasil penelitian Asmalidar (2017) usia, IPK, tempat tinggal, asal perguruan tinggi, juga berpengaruh terhadap literasi keuangan Bank Syariah mahasiswa Politeknik Medan dan Universitas Sumatra Utara. Sedangkan jenis kelamin, lama kuliah, dan pendapatan orangtua tidak berpengaruh terhadapt literasi keuangan mahasiswa Politeknik Medan dan Universitas Sumatra Utara. Artinya, faktor usia, IPK, tempat tinggal, asal perguruan tinggi berpengaruh terhadap kesadaran pembelian produk perbankan syariah Mahasiswa Politeknik Medan dan Universitas Sumatera Utara. Kedua penelitian diatas menunjukan, ada beberapa faktor yang membuat kesadaran masyarakat akan produk perbankan syariah. ${ }^{9}$

${ }^{8}$ Farida, Analisis Faktor-fakator yang mempengaruhi tingkat literasi mahasiswa S1 Fakultas Ekonomi Universitas Andalas 2016.

9 Asmalidar. Analisis Faktor-faktor yang mempengaruhi tingkat literasi keuangan mahasiswa di Kota Medan (Studi Kasus Mahasiswa Politeknik Negeri Medan Jurusan Akuntansi dan Mahasiswa Fakultas Ekonomi USU. UPPM Polmed), 2017. 


\section{Bagus Romadhon | Korelasi Merger Tiga Bank...}

\section{Metode}

Penelitian ini dilakukan Kajian Pustaka dan Pemikiran Kritis dari Penulis. Jenis data yang digunakan adalah data primer dan sekunder. Data primer dari beberapa jurnal. Data sekunder dari buku, ujian akhir dan internet. Metode analisis data yang digunakan adalah pendekatan kuantitatif untuk mengumpulkan data-data fakta dari beberapa pemikiran penulis.

\section{Hasil dan Pembahasan}

Perbankan Syariah di Indonesia memiliki sejarah yang panjang. Awalnya pada tahun 1983 ada rencana besar tentang Bank Syariah di Indonesiai. Saat itu pemerintah mulai melakukan pengurangan syarat terhadap perbankan di Indonesia.

Pemerintah berharap dengan deregeluasi ini, tercipta efesiensi sehingga menjadi penopang perekonomian di Indonesia yang saat itu belum terlalu stabil. Yang menarik, pada tahun yang sama, pemerintah juga melakukan memulai menggunakan sistem 'bagi hasil' yang dikenal dari sistem dari Perbankan Syariah.

Selanjutnya, gagasan Perbankan Islam dipraktekkan dalam skala yang relative kecil dan terbatas. Di antaranya di Bandung (Bait At-Tamwil Salman ITB).

Tahun 1990, Majelis Ulama Indonesia (MUI) membentuk kelompok kerja untuk mendirikan Bank Islam di Indonesia. Pada tanggal 18-20 Agustus 1990, Majelis Ulama Indonesia (MUI) menyelenggarakan lokakarya bunga bank dan perbankan di Cisarua, Bogor, Jawa Barat. ${ }^{10}$

Hasil lokakarya tersebut kemudian dibahas lebih mendalam pada Musyawarah Nasional IV MUI di Jakarta 22-25 Agustus 1990. Yang

10 https://www.ojk.go.id/id/kanal/syariah/tentangsyariah/Pages/Sejarah PerbankanSyariah.aspx 


\section{Bagus Romadhon | Korelasi Merger Tiga Bank...}

menghasilkan amanat bagi pembentukan kelompok kerja pendirian bank Islam di Indonesia.

Kelompok kerja dimaksud disebut Tim Perbankan MUI dengan diberi tugas untuk melakukan pendekatan dan konsultasi dengan semua pihak yang terkait. Sebagai hasil kerja Tim Perbankan MUI tersebut adalah berdirilah bank syariah pertama di Indonesia yaitu PT Bank Muamalat Indonesia (BMI). Sesuai akte pendiriannya, berdiri pada tanggal 1 Nopember 1991. Sejak tanggal 1 Mei 1992, BMI resmi beroperasi dengan modal awal sebesar Rp 106.126.382.000,00 11

Pada awal masa operasinya, keberadaan bank syariah belum memperoleh perhatian yang optimal dalam tatanan sektor perbankan nasional. Landasan hukum operasi bank yang menggunakan sistem syariah, saat itu hanya diakomodir dalam salah satu ayat tentang "Bank dengan sistem bagi hasil" pada UU No. 7 Tahun 1992, tanpa rincian landasan hukum syariah serta jenis-jenis usaha yang diperbolehkan.

Pada tahun 1998, pemerintah dan Dewan Perwakilan Rakyat (DPR) melakukan penyempurnaan UU No. 7/1992 tersebut menjadi UU No. 10 Tahun 1998, yang secara tegas menjelaskan bahwaterdapat dua sistem dalam perbankan di tanah air (dual banking system),yaitu sistem perbankan konvensional dan sistem perbankan syariah. ${ }^{12}$

Peluang ini disambut hangat masyarakat perbankan, yang ditandai dengan berdirinya beberapa Bank Islam lain, yakni Bank IFI, Bank Syariah Mandiri, Bank Niaga, Bank BTN, Bank Mega, Bank BRI, Bank Bukopin, hingga bank-bank Daerah juga mendirikan Bank Syaria. Semisal BPD Jabar dan BPD Aceh.

\footnotetext{
11 https://www.ojk.go.id/id/kanal/syariah/tentangsyariah/Pages/Sejarah PerbankanSyariah.aspx Syariah.aspx

12 https://www.ojk.go.id/id/kanal/syariah/tentangsyariah/Pages/Sejarah Perbankan-
} 


\section{Bagus Romadhon | Korelasi Merger Tiga Bank...}

Sejak mulai dikembangkannya sistem Perbankan Syariah di Indonesia, dalam dua dekade pengembangan keuangan syariah nasional, sudah banyak pencapaian kemajuan. Baik dari aspek lembagaan dan infrastruktur penunjang, perangkat regulasi dan sistem pengawasan, maupun awareness dan literasi masyarakat terhadap layanan jasa keuangan syariah.

Sistem keuangan syariah kita menjadi salah satu sistem terbaik dan terlengkap yang diakui secara internasional. Per Juni 2015, industri perbankan syariah terdiri dari 12 Bank Umum Syariah, 22 Unit Usaha Syariah yang dimiliki oleh Bank Umum Konvensional dan 162 BPRS dengan total aset sebesar Rp. 273,494 Triliun dengan pangsa pasar 4,61\%. ${ }^{13}$

Berbagai kemajuan Perbankan Syariah dari tahun ke tahun ini tentu menjadikan Bank Syariah Indonesia (BSI) menjadi garda terdepan dalam perbankan nasional. Dengan adanya merger tiga Bank Syariah dengan entetitas terbesar di Indonesi ini akan mendorong Perbankan Syariah lebih memiliki daya saing dengan era digital ini.

Ada tiga jenis produk Bank Syariah yang sudah dikenal masyarkat Indonesia yakni Produk penghimpun dana (funding), Produk penyaluran dana (lending), dan Produk jasa (service).

A. Produk Penghimpunan dana (funding)

1. Giro wadi'ah adalah produk pendanaan bank syariah berupa simpanan dari nasabah dalam bentuk rekening giro untuk keamanan dan kemudahan pemakaiannya.

13 https://www.ojk.go.id/id/kanal/syariah/tentangsyariah/Pages/Sejarah PerbankanSyariah.aspx 


\section{Bagus Romadhon | Korelasi Merger Tiga Bank...}

2. Produk Tabungan. Dalam hal ini terdapat dua prinsip perjanjian Islam yang sesuai diimplementasikan dalam produk perbankan berupa tabungan yaitu wadi'ah dan mudharabah.

3. Deposito merupakan produk dari bank yang memang ditunjuk untuk kepentingan investasi dalam bentuk surat-surat berharga, sehingga dalam perbankan syari'ah akan memakai prinsip mudharabah.

B. Jenis produk yang kedua adalah menyalurkan dananya kepada nasabah produk pembiayaan syariah.

Terbagi dalam 4 kategori yaitu pembiayaan dengan prinsip jual beli, pembiayaan dengan prinsip Ijarah, pembiayaan dengan bagi hasil, dan yang terakhir dengan akad pelengkap.

C. Jenis Produk yang ketiga adalah produk jasa yang terdiri dari Sharf (Jual Beli Valuta Asing) dan Ijarah (sewa).

Begitu banyak produk Perbankan Syariah yang dapat digunakan dalam keseharian masyarakat. Semua produk tersebut tentu sudah sesuai dengan syariat Islam.

Ada beberapa faktor yang bisa menjadi pendorong percepatan BSI adalah terus diberikannya literasi produk perbankan syariah di Indonesia.

Tujuan Literasi Keuangan, (a) meningkatnya kualitas pengambilan keputusan keuangan individu dan, (b) perubahan sikap dan perilaku individu dalam pengelolaan keuangan menjadi lebih baik, sehingga mampu menentukan dan memanfaatkan lembaga, produk dan layanan jasa keuangan 


\section{Bagus Romadhon | Korelasi Merger Tiga Bank...}

yang sesuai dengan kebutuhan dan kemampuan Konsumen dan/atau masyarakat dalam rangka mencapai kesejahteraan. ${ }^{14}$

Literasi keuangan syariah harus mengacu kepada Syariat Islam, yaitu berdasarkan pada hukum Islam. Ada tiga kategori produk untuk muslim yakni halal, haram, dan mushbooh. Halal dalam bahasa arab berarti diizinkan, bisa digunakan, dan sah menurut hukum. Kebalikan dari halal adalah haram yang berarti tidak diizinkan, tidak bisa digunakan, dan tidak sah menurut hukum sedangkan mushbooh (syubha, shubhah, dan mashbuh) berarti hitam putih, masih dipertanyakan, dan meragukan oleh karena itu sebaiknya dihindari. ${ }^{15}$

. Dengan adanya merger, dana untuk pengelolaan literasi keuangan kepada masyarakat tentu juga akan meningkat. Dalam pemberitaan beberapa waku lalu, Wakil Presiden RI, yang juga salah satu pendiri Bank Syariah pertama di Indonesia , KH Mahruf Amin berharap dengan adanya merger tiga bank syariah membuat Indonesia menjadi Pusat Ekonomi Islam Secara global. "BSI sebagai salah satu piranti ekonomi dan keuangan syariah harus menjadi sebuah pilihan yang rasional bagi masyarakat sehingga tidak menjadi eksklusif," ungkapnya dilansir dari Warta Ekonomi.id.

Hal itu, juga mendapat dukungan dari Hery Gurardi Direktur utama BSI. Hery optimistis dalam tiga tahun kedepan, BSI dapat masuk 5 besar kapitalis secara Global. ${ }^{16}$

Dalam beberapa kajian, setidaknya ada empat 7 faktor yang membuat Bank Syariah kurang diminati masyarakat diminati. (a) Masih kurangnya

\footnotetext{
${ }^{14}$ Antonio, Muhammad Syafi'i. (2001). Bank Syariah: dari Teori ke Praktik. Jakarta: Gema Insani.

${ }^{15}$ Wahyuny, I. N. (2015, November). Pengembangan Pendidikan Financial Literacy Berbasis Nilai-Nilai Anti Korupsi Sebagai Investasi Sosial: Sebuah Pemikiran. In Prosiding Seminar Pendidikan Ekonomi dan Bisnis (Vol. 1, No. 1).

${ }^{16}$ https://www.wartaekonomi.co.id/read329477/BSI
} 


\section{Bagus Romadhon | Korelasi Merger Tiga Bank...}

kesadaran masyarakat untuk mengenali bank syariah. (b) Jaringan operasional bank syariah yang masih terbatas dibandingkan dengan bank konvensional. (c) Soisialisasi yang dilakukan bank syariah masih kurang dibandingkan dengan bank umum lainnya . (d) Umur, mempengaruhi terhadap daya tangkap dan pola pikir seseorang. Semakin bertambah umur dan pengetahuan seseorang maka akan semakin berkembang pula daya tangkap dan pola fikirnya, sehingga pengetahuan yang diperolehnya semakin membaik. Dan sebaliknya apabila bertambah umur seseorang tetapi tidak memiliki pengetahuan maka semakin kurang pula daya tangkap dan pola fikirnya, sehingga pengetahuan yang didapat kurang baik. (e) Pendidikan, adalah suatu usaha untuk mengembangkan kepribadian dan kemampuan di dalam dan di luar sekolah dan berlangsung seumur hidup. Dengan pendidikan tinggi maka seseorang akan cenderung untuk mendapatkan informasi. baik dari orang lain maupun dari media massa. Semakin banyak informasi yang masuk semakin banyak pula pengetahuan yang didapat. Sedangkan sebaliknya semakin rendah pendidikan seseorang semakin kurang daya tangkap untuk mendapatkan suatu informasi. (f) Pekerjaan, jenis pekerjaan dapat membuat masyarakat merasa ada beberapa bankn yangcocok dengan dirinya. (g) Sosial,Budaya, dan Ekonomi Kebiasaan dan tradisi yang dilakukan melalui penalaran apakah yang dilakukan baik atau buruk. Dengan demikian seseorang akan bertambah pengetahuannya walaupun tidak melakukan. Status ekonomi seseorang juga akan menentukan tersedianya suatu fasilitas yang diperlukan untuk kegiatan tertentu, sehingga status sosial ekonomi ini akan mempengaruhi pengetahuan seseorang. sedangkan masyarakat yang sosial, budaya, ekonomi yang kurang baik kebiasan dan tradisi yang dilakukan tanpa melakukan. 


\section{Bagus Romadhon | Korelasi Merger Tiga Bank...}

Dari ketujuh faktor tersebut, setidaknya ada 3 faktor utama yang terpecahkan dengan adanya mereger ini. Yakni faktor ketidaktahuan Produk Bank Syariah, jaringan operasional Bank Syariah dan Sosialiasi akan produk Bank Syariah.

Dengan merger, dana kelolaan Bank Syariah pun akan naik dengan signifikan. Sehingga dana yang digunakan untuk literasi keuangan pun akan semakin optimal. Tercatat kinerja semester I-2020 total aset BSI hasil merger mencapai Rp 214,6 triliun dengan modal inti lebih dari Rp 20,4 triliun Dengan optimalnya dana literasi keuangan, maka dengan seiringanya waktu, BSI akan lebih cepat dikenal oleh masyarakat.

Jaringan operasional BSI pun akan semakin banyak. Satu Kota bahkan akan memiliki beberapa Kantor BSI. Sehingga jaringan BSI akan semakin kuat. Dan tidak alasan masyarakat kekurangan jaringan operasional. Sementara untuk empat Faktor lainya adalah bersifat ke personal masyarakat langsung. Maka dengan demikian, ada juga campur tangan steakholder lainnya untuk membuat kesadaran literasi produk Perbankan Syariah.

\section{Kesimpulan}

Mergernya tiga bank Syariah menjadi Bank Syariah Indonesia, (BSI) diprediksi akan berpengaruh cukup signifikan terhadap kesadaran masyarakat terhadap produk Perbankan Syariah. Dengan dana kelola yang naik secara signifikan, diperkiraan dana literasi keuangan untuk produk BSI akan naik secara drastis sehingga masyarakat lebih cepat dalam mengetahui produkproduk Bank Syariah. Selain itu, jaringan operasional BSI menjadi jauh lebih banyak sehingga memudahkan masyarakat dalam bertransaksi. Peneliti berharap BSI yang terus memberikan sosialisasi akan produk perbankan syariah sehingga kesadaran masyarakat semakin optimal. 


\section{Bagus Romadhon | Korelasi Merger Tiga Bank...}

\section{Daftar Pustaka}

Antonio, Muhammad Syafi'i. Bank Syariah: dari Teori ke Praktik. Jakarta: Gema Insani. 2001.

Asmalidar, Analisis Faktor-faktor yang mempengaruhi tingkatliterasi keuangan mahasiswa di Kota Medan (Studi Kasus Mahasiswa Politeknik Negeri Medan Jurusan Akuntansi dan Mahasiswa Fakultas Ekonomi USU. UPPM Polmed), 2017.

https://www.ojk.go.id/id/kanal/syariah/tentangsyariah/Pages/Sejarah Perbankan-Syariah.aspx

https://www.wartaekonomi.co.id/read329477/BSIhttps://lokadata.id/artikel/p engamat-jumlah-sdm-dan-cabang-jadi-tantangan-bank-syariahindonesia

https://databoks.katadata.co.id/datapublish/2019/09/25/indonesia-negaradengan-penduduk-muslim-terbesar-dunia

Hasanah, Wirdatul, Tingkat Pengetahuan Masyarakat Terhadap Produk Perbankan Syariah Dikelurahanlanggini Kota Bangkinang Kabupaten Kampar, 2013.

Nasution, Anriza Witi, Marlya Fatira AK EQUILIBRIUM: Jurnal Ekonomi Syariah Volume 7, Nomor 1, 2019. 